\title{
REgUlatory CHALLENGES OF AIRPORT SLOT ALLOCATION IN THE EUROPEAN UNION*
}

\author{
JAKUB KOCIUBIŃSKI**
}

\section{INTRODUCTION}

Since the beginning of commercial aviation, the right to take off and land and has been allocated on a first-come first-served basis with scarcely any coordination between carriers and/or airport management. ${ }^{1}$ Over the years, as air traffic increased and major airports became congested, access to their runways has become increasingly difficult. ${ }^{2}$ Beginning in the late $1960 \mathrm{~s}$, long queues of airplanes waiting on taxiways or in holding areas to take off or land became a common sight at major international airports during peak times. $^{3}$ This, in turn, resulted in serious inefficiencies in carriers' air operations. ${ }^{4}$

In response to this situation, the notion of a 'slot' was developed. ${ }^{5} \mathrm{~A}$ slot amounts to the right to use a runway at a specified time on a specified day. ${ }^{6}$ The capacity of each airport - the total number of slots per day depends on a large number of technical, safety and environmental factors such

DOI: $10.2478 /$ wrlae-2013-0003

* The project has been financed by the National Science Centre as per decision DEC2012/07/B/HS5/03951

** PhD in Law, Assistant Professor, University of Wroclaw, Department of International and European Law; kociubinski.jakub@prawo.uni.wroc.pl

${ }^{1}$ Daniele Condorelli, 'Efficient and Equitable Airport Slot Allocation' in Claudio A Piga and Maria José Gil-Moltó (eds) [2007] I-II Rivista di Politica Economica. The Liberalisation of the European Civil Aviation Industry: Economic and Policy Implications 81.

${ }^{2}$ Martin Stainland, Europe of the Air? The Airline Industry and European Integration

(Rowman \& Littlefield Publishers 2008) 163.

${ }^{3}$ Condorelli (n 1) 81; Amadeo Odoni, 'Airports' in Peter Belobaba, Amadeo Odoni and Cynthia Barnhart, The Global Airline Industry (Wiley 2009) 343.

4 ibid.

5 ibid, Stainland (n 2) 163.

6 Typically this interval of time reserved for the arrival or departure of a flight becomes associated with a particular flight operation. While the notion is largely constructed around the right to take off and land (usage of the runway) it could also encompass rights to use a variety of other resources necessary for airlines to operate at an airport. Rights to these other non-runway capacities could be of importance where airport users are facing infrastructurerelated constraints that would negatively impact the ability to use runway rights, such as terminal capacity. 
as the need to provide spacing between aircraft, etc. ${ }^{7}$ However, the most critical factor is, unsurprisingly, the total number of active runways at a given airport. Runways are indeed 'a rare commodity'. Construction of a runway itself is very expensive as it requires extensive technical and electronic infrastructure as well as the application of advanced technologies and the use of high quality materials. ${ }^{8}$ Furthermore, as planning procedures becoming increasingly rigorous and local residents and environmental activists, who are typically fiercely opposed to such construction, become better organized and more outspoken, the process of construction is slowed significantly and can take many years (in no small part due to legal challenges). ${ }^{9}$ As a result, the number of slots at any given airport is relatively rigid, while demand for them is constantly on the rise. ${ }^{10}$ In other words, airport capacity is a bottleneck for air traffic. ${ }^{11}$

In order to develop and sustain an efficient, non-discriminatory system for rationing available slots, a few crucial questions must be addressed. Should slots be allocated by way of commercial (monetary) transactions, or be allotted freely? Who should be responsible for this allocation - a public regulator or private entity? Who should have the first claim on available slots - well-established carriers or new entrants? On the eve of reform of the European Union's (EU) slot distribution system it is also vital to explore various alternative possibilities (either administrative or market-based) based on experiences with the current system and its shortcomings. ${ }^{12}$ The point of departure for this analysis is an overview of the

\footnotetext{
${ }^{7}$ For details see Amadeo Odoni Richard de Neufville, Airport Systems: Planning, Design, and Management (McGraw-Hill 2003) and Alexander T Wells (ed), Airport Planning \& Management (McGraw-Hill 1996).

${ }^{8}$ Stainland (n 2) 163.

${ }^{9}$ ibid.

${ }^{10}$ For example, capacity available at the airport in terms slots per hour for selected European airports is as follows: Copenhagen (CPH) - 83; Dublin (DUB) - 44; Frankfurt (FRA) - 80; London Gatwick (LGW) - 46; London Heathrow (LHR) - 87; London Stansted (STN) - 42; Madrid Barajas (MAD) - 78; Milan Malpensa (MXP) - 70; Paris Charles de Gaulle (CDG) - 97; Amsterdam Schipol (AMS) - 106. Source: IATA.

11 According to EUROCONTROL forecasts, in the European Union alone, even assuming the absence of any external disturbances, by the year 2030 thirteen of the top 25 European airports will experience a probability exceeding $75 \%$ of having an average departure delay of more than 15 minutes for at least four hours a day. An important finding relevant in the current analysis is that performance degradation produced by congestion does not increase linearly with the increase in congestion; degradation occurs faster as congestion increases. When the average airport level of congestion in the network approaches the level forecasted for 2030, a relative small additional increase in congestion implies non-proportional increases in the number of overloads or in reactionary delay, especially at the worst hours of the day. Marta Sanchez Cidoncha, (ISDEFE), Ricardo Herranz (INNAXIS), Network Congestion 2030. Technical Volume 2 - Congested Network Response Assessment (EUROCONTROL 2010)

12 On 1 December 2011 the Commission adopted the so-called 'Better Airport' document, which includes a set of proposals aimed at achieving better usage of scarce airport capacity. According to analysis carried out by the Commission, the changes proposed could be worth $€ 5$ billion to the European economy and create 62,000 more jobs over the period 2012-2025, and would allow the system to handle 24 million more passengers a year by 2025 . The following regulation is proposed: Proposal for a Regulation of the European Parliament and the Council on common rules for the allocation of slots at European Union airports, COM/2011/0827 final - 2011/0391 (COD).
} 
main features of the current slot allocation system, which will be followed with a review of various alternative solutions.

\section{Communautaire System of Slots Allocation - AN OVERVIEW}

Council Regulation 95/93 (amended by regulations 793/2004 and $545 / 2009$ ) provides common rules for slot allocation in the European Union. ${ }^{13}$ These rules apply only to so-called 'coordinated airports'. ${ }^{14}$ Each Member State can designate any airport as such, although they are under no obligation to do so. ${ }^{15}$ They are, however, required to carry out a capacity analysis, and then to designate an airport as 'coordinated' if the following criteria are met: first, when carriers representing more than half of air operations of the given facility and/or its management consider that capacity is insufficient (for actual or planned operations) $;{ }^{16}$ second, when de novo entrants encounter serious problems with obtaining and securing slots; ${ }^{17}$ finally, when the Member State, following consultations with carriers, representative organisations, airport management, air traffic management and passenger's organizations, reaches the conclusion that such problems can not be solved in the short term, making this designation necessary. ${ }^{18}$

The system is based on a 'coordinator', which must be appointed at each coordinated airport. ${ }^{19}$ The Member States must ensure that coordinators carry out their duties in an independent manner. ${ }^{20}$ This in turn allows them to act in a 'neutral, non-discriminatory and transparent way'. ${ }^{21}$ Additionally, Member States are required to set up a 'co-ordination committee' to provide consultative capacity. ${ }^{22}$ Participation in this committee is open to air carriers

\footnotetext{
${ }^{13}$ Council Regulation (EEC) 95/93 of 18 January 1993 on common rules for the allocation of slots at Community airports [1993] OJ L14/1; Regulation (EC) 793/2004 of the European Parliament and of the Council of 21 April 2004 amending Council Regulation (EEC) 95/93 on common rules for the allocation of slots at Community airports [2004] OJ L138/50; Regulation (EC) 545/2009 of the European Parliament and of the Council of 18 June 2009 amending Regulation (EEC) 95/93 on common rules for the allocation of slots at Community airports [2009] OJ L167/24.

${ }^{14}$ See also Communication from the Commission to the European Parliament, the Council, the European Economic and Social Committee and the Committee of the Regions on the application of Regulation (EEC) No 95/93 on common rules for the allocation of slots at Community airports, as amended COM [2007] 0227 final; Communication from the Commission Communication on the application of Regulation (EC) 793/2004 on common rules for the allocation of slots at Community airports COM [2007] 0704 final.

${ }^{15}$ Article 3 (1) of the Regulation 95/93. In every subsequent citation of this regulation the consolidated version including both amendments will be quoted.

${ }^{16}$ Article 3 (2) i of the Regulation 95/93.

${ }^{17}$ Article 3 (2) ii of the Regulation 95/93.

${ }_{18}$ Article 3 (2) iii of the Regulation 95/93.

${ }^{19}$ Article 4 of the Regulation 95/93.

${ }^{20}$ Article 4 (2) of the Regulation 95/93.

${ }^{21}$ Article 4 (3) of the Regulation 95/93.

${ }^{22}$ Article 5 of the Regulation 95/93.
} 
and their representative organisations as well as airport authorities and air traffic management. ${ }^{23}$

The allocation mechanism is based on the following principles: slots are allocated for free to carriers, which in turn pay airport charges only upon effective usage of a given slot. ${ }^{24}$ An air carrier which continuously and effectively uses a given slot for a season (reference period) is entitled to claim that slot in the next equivalent season, ${ }^{25}$ thus acquiring so-called 'grandfather rights' ${ }^{26}$ All remaining slots are put into a 'slot pool' ${ }^{27}$ half of which must be allocated to 'new entrants'. ${ }^{28}$ A new entrant is an air carrier requesting slots at an airport on any day and holding or having been allocated fewer than four slots at that airport on that day, or an operator requesting slots for non-stop service between two EU airports where at most two other carriers operate a direct service between those airports or airport systems on that day and holding or having been allocated fewer than four slots at that airport on that day for that non-stop service. ${ }^{29}$ The above is provided that in both cases the air carriers do not hold more than $3 \%$ of the total daily slots at a given airport or more than $2 \%$ of the total slots throughout an airport system of which that airport forms part. ${ }^{30}$ A new entrant who has been offered slots within two hours of the requested time but declines the offer loses its 'new entrant' status. $^{31}$ The remaining slots should be allocated in a 'neutral, nondiscriminatory and transparent' manner. ${ }^{32}$ If it is not possible to meet all demands, preference must be given to commercial air services (at the expense of general aviation) and in particular to scheduled and programmed nonscheduled operations. ${ }^{33}$ In other circumstances allocation is at the coordinator's discretion. ${ }^{34}$

23 ibid.

${ }^{24}$ Article 8 of the Regulation 95/93.

${ }^{25}$ Article 8(1) a, Article 10 of the Regulation 95/93.

26 ibid.

${ }^{27}$ Article 10 of the Regulation 95/93.

${ }^{28}$ Article 10 (7) of the Regulation 95/93.

${ }^{29}$ Article 10 (2)b of the Regulation 95/93.

30 As per Regulation 95/93 (Article $2 \mathrm{~h}$ ), an airport system is defined as two or more airports grouped together and serving the same city or conurbation. The identification of an airport within a given urban area became problematic when low-cost carriers began using more distant (from metropolitan areas) airports such as Brussels-Charleroi, Vitoria-Gasteiz (Bilbao) or Paris-Beauvais. The chief concern is how to classify these airports. The question boils down to the issue of whether the air services of low-cost carriers could be regarded as competition for those offered by full-service operators; this would imply that airports serviced by both categories of carriers would be regarded as parts of one system. See Commission Notice on the definition of the relevant market for the purposes of Community competition law, [1997] OJ C372/5. See also Jakub Kociubiński, 'Relevant Market in Commercial Aviation in European Union' (2011) 1 WRLAE 12.

${ }^{31}$ Article 10 (2) of the Regulation 95/93.

${ }^{32}$ Article 4 (3) of the Regulation 95/93.

${ }^{33}$ Article 8 (1)b of the Regulation 95/93.

34 ibid. 


\section{The Issue of Slots Trading - Slots as a Property Right OR A LICENCE?}

As mentioned before, slots are allocated free of charge, and under current rules the sale of these slots is not allowed. However, the slots in question may be 'freely exchanged between air carriers or transferred by air carriers from one route, or type of service, to another, by mutual agreement or as a result of a total or partial take-over or unilaterally'.35

This somewhat ambiguous provision raises concerns regarding the legal status of a slot. ${ }^{36}$ The matter boils down to the question of who actually owns a slot - the Member State, the airport or the air carriers themselves? ${ }^{37}$ The European Commission (EC) consistently argues that the rights of air carriers over slots is limited only to the right of usage and do not amount to property rights. ${ }^{38}$ For example, former competition commissioner Karel Van Miert openly stated that runway slots are public property and regarded airlines' operations as a public service. ${ }^{39}$ Under this approach, airport slots would represent nothing more than a temporary utilization licence. ${ }^{40}$ This would mean that airlines may only exchange slots and not transfer them, since transfer implies ownership while exchange is merely redistribution. ${ }^{41}$ In light of this reasoning, it remains unclear whether exchange may incorporate a monetary element and be conducted following a 'slot for slot-plus-cash' manner. ${ }^{42}$

This issue came to the fore in the British Airways/American Airlines (I) case where in the event of conclusion of a proposed alliance the incumbent 'owner' of the transferred slots would receive financial compensation. ${ }^{43}$ The alliance failed to materialize, so neither the EC nor European Court of Justice (ECJ) had the opportunity to deliver an authoritative response to the question

\footnotetext{
${ }^{35}$ Article 8(4) of the Regulation 95/93.

${ }^{36}$ Since the inception of the notion of 'slot' its legal status has fuelled considerable debate. See inter alia Stainland (n 2) 176; Achim I Czerny, Peter Forsyth, David Gillen and HansMarin Niemeier (eds) Airport Slots. International Experiences and Options for Reform (G.E.R.S. 2008); Margherita Colangelo, Creating Property Rights. Law and Regulation of Secondary Trading in the European Union (Martinus Nijhof Publishers 2012) 62.

37 ibid. Keith Boyfield, 'Who Owns Airport Slots? A Market Solution to a Deepening Dilemma' in Keith Boyfield, David Starkie, Tom Bass, Davis Humphreys, Markets in Airport Slots (IEA 2003) 21.

${ }^{38}$ See (n 13).

39 The former Competition Commissioner, Karel Van Miert, reacted on 10.08.1998 to the approach adopted by the Office of Fair Trading (UK competition authorities) to the British Airways/American Airlines alliance. The Commissioner repeated that the sale of slots, (the possibility of which has not been ruled out by the UK) is not allowed under Regulation 95/93. This possibility is also contrary to EU competition rules, for it shows undue favouritism to incumbent operators which historically have privileged position at their home airports. For the relevant data see infra (n 55).

${ }^{40}$ For the purposes of the current analysis the licence could be defined as the conferring of permission by a grantor to a grantee to use in accordance with the terms and conditions set out in each licence or imposed through regulations.

${ }^{41}$ Stainland (n 2) 176.

${ }^{42}$ Bill Allan, Mark Furse and Brenda Sufrin (eds), Butterworths Competition Law 3 - Issue 78 (Lexis Nexis 2008) IX-305.

${ }^{43}$ See Notice British Airways/American Airlines (I) [1998] OJ C239/10.
} 
at hand. ${ }^{44}$ This lex lacunae effectively creates a 'grey market' for trade in slots where commercially valuable slots (usually these in peak hours) are exchanged for less attractive ones (off-peak). ${ }^{45}$ The Commission's requirement for exchange was thus formally met while at the same time the beneficiary reaped substantial profit. ${ }^{46}$

The genesis of this debate regarding the legal status of a slot is glaringly obvious, as it boils down to who should benefit from the income generated by the potential sale of slots (the airport, a third party, the public regulator, etc.). ${ }^{47}$ This decision will always be a fundamentally political one, as it could be used as a tool for achieving policy-defined fiscal objectives. ${ }^{48}$ At the same time, the choice of beneficiary would have a significant impact on the overall structure of the market. For example, if the profits from slot trading are handed over to airports, they will have little incentive to increase capacity as they would not want to lose income from the existing slots whose scarcity results in premium prices. ${ }^{49}$ Even if one assumes that increases in capacity would be financed from the public purse, the subsequent larger scale of operations (and possible overcapacity) may not be as profitable as a situation in which demand exceeds supply ${ }^{50}$. In other words, this system would constitute the establishment of a de facto fiscal monopoly, which is prohibited under the so-called 'standstill clause'. ${ }^{51}$ Also, a situation when a State retains the authority to 'sell' slots may - depending on the State concerned - be susceptible to corruption without a guarantee that incumbents could not push competitors out of the market. ${ }^{52}$

With these considerations in mind, the following logic of the current mechanism emerges: the incentive of competition is lost, since there is no real

\footnotetext{
44 The proposed alliance had raised serious concerns regarding its dominance over transAtlantic hub-to-hub operations (chiefly London-Heathrow - Chicago; London-Gatwick Dallas Fort Worth; London-Heathrow - Miami) Stephen McShea, 'The "Dominant Position" Doctrine and the European Union's Response to the British Airways / American Airlines Alliance' 23 (1999) Boston College International and Comparative Law Review 71.

${ }^{45}$ Stainland (n 2) 176; Matthias Kilian, 'The Development of the Regulatory Regime of Slot Allocation in the EU' in Czerny, Forsyth, Gillen and Niemeier (n 35) 257.

${ }^{46}$ ibid.

${ }^{47}$ Nicolas Gruyer and Nathalie Lenoir, ‘Auctioning Airport Slots (?)' [2003] 1 LEEA ENAC Economic Working Papers 1.

48 ibid. The policy rationale behind this decision is to capture funds that under the current legal regime pass (albeit not entirely officially) between carriers (Stainland (n 2) 180).

49 ibid.

50 ibid.

51 The 'standstill' clause is a provision addressed to Member States according to which existing commercial monopolies, although not explicitly forbidden under Article 37 TFEU (Treaty of the Functioning of European Union [2010] OJ L83/47), have to be adjusted to be compliant with fundamental principles of the Internal Market especially with the principle of non-discrimination, and the introduction of new measures (new monopolies) is forbidden. See José Louis Buendia Sierra, 'Article 86 - Exclusive Rights and Other Anti-competitive State Measures' in Jonathan Faull and Ali Nikpay (eds), The EC Law of Competition (OUP 2007) 622.

52 The relationship between the state (regulator) and various commercial actors, especially in a situation when transfers of public funds are involved, is particularly prone to the occurrence of a situation called 'State Capture'. This essentially describes cases when certain undertakings are able to shape the rules of the game to their advantage through illicit and non-transparent measures.
} 
link between the commercial value of a given slot as measured by the time of day to which it is assigned (broadly, peak hours mean higher profits) and the actual investment by the airline to acquire it. So, from the incumbent's perspective, the simple retention of slots itself is desirable so as to block potential competitors. In other words, conditions are favourable to anticompetitive practices. ${ }^{53}$ However, the current system addresses these concerns by providing a mechanism to prevent the withholding of unused slots. This will be discussed in the next section.

\section{GRANDFATHER RIGHTS AND “USE-IT-OR-LOSE-IT" RULE}

The air transport industry was traditionally shielded from the full impact of EU competition rules. ${ }^{54}$ This changed after Nouvelles Frontiéres, nevertheless many flag carriers inherited privileged positions at their home airports. ${ }^{55}$ The focus of competition authorities was shifted to scrutinizing the behaviour of these established airlines for "concerted practices" and abuses of "dominant position". 56 In other words (as mentioned in the previous paragraph), the system is prone to situations in which incumbent operators retain slots so as to stop new competitors from entering the market.

This anti-competitive behaviour has been further augmented by a block exemption establishing so-called 'grandfather rights' (historical precedence) ${ }^{57}$ If an incumbent carrier operates its slots with a utilization rate at $80 \%$ or above during the summer (April to October) or winter scheduling (reference) period, it is entitled to the same slots in the equivalent scheduling period of the following year. ${ }^{58}$

As a remedy for the concerns regarding potential anti-competitive abuse of 'grandfather rights', the notion of 'Use-it-or-lose-it' was

\footnotetext{
${ }^{53}$ See in this context analysis in infra (n 122).

${ }^{54}$ Allan, Furse and Sufrin (n 42) IX-173 - IX-174.

55 Joined Cases 209/84, 210/84, 211/84, 212/84, 213/84 and 214/84, Criminal proceedings against Lucas Asjes and Others, Andrew Gray and Others, Jaques Maillot and Others, and Léo Ludwig and Others (Nouvelles Frontiéres ) [1968] ECR 1425, para 31, 32, 40 - 42 and 45 and also Case 167/73 Commission v France (French Seamen) [1974] ECR 359.

56 The issue of concentration at selected EU and US network hubs clearly demonstrates the privileged position of flag carriers at their home airports in comparison to the following two leading carriers: Amsterdam Schipol (AMS); KLM - 50.7\%, Transavia - 5.3\%, easyJet 3.5\%; Munich (MUC); Lufthansa - 64\%, dba - 7.8\%, Air France - 1.8\%; Paris Orly (ORY); Air France $-61.3 \%$, Iberia - 7.5\%, easyJet - 5.6\%; Paris Charles de Gaulle (CDG); Air France $-57.9 \%$, Lufthansa - 5.2\%, British Airways - 4\%; Frankfurt (FRA); Lufthansa $60.1 \%$, British Airways - 3.2\%, Condor - 2.3\%; Milan Malpensa (MXP); Alitalia - 59.1\%, Lufthansa - 7.1\%, Air France 3.6\%; London (LHR); British Airways - 42.3\%, BMI - 11.5\%, Lufthansa - 4.5\%; Madrid Barajas (MAD); Iberia - 56.7\%, Spanair - 13.7\%, Air Europa $6.8 \%$. In the USA there are no national carriers as there are in the EU, but the same mechanism applies to the status of large airlines at their home airports. Source: David Starkie, 'The Dilemma of Slot Concentration at Network Hubs' in Czerny, Forsyth, Gillen and Niemeier (n 36) 194.

57 Batool Menaz and Bryan Matthews, 'Economics Perspectives of Slot Allocation' in Czerny, Forsyth, Gillen and Niemeier (n 36) 26; Małgorzata Polkowska, 'Zasady tworzenia jednolitego europejskiego rynku usług lotniczych' (2004) 4 Studia Europejskie 60.

${ }^{58}$ Article 10 (3) of the Regulation 95/93.
} 
established. ${ }^{59}$ Under this rule, slots that are used less than the aforementioned $80 \%$ of the time in a given season are deemed to have been forfeited and must be returned to the 'pool'. ${ }^{60}$ In addition, a Member State may withhold slots from the pool provided they are required for domestic services of significance to regional economic development. ${ }^{61}$

From the standpoint of long-term strategic planning, the current system of slot precedence is certainly beneficial. ${ }^{62}$ However, it is encumbered with a serious drawback, as it does not foster allocative efficiency. ${ }^{63}$ The general logic of the system does not ensure that slots reach the operators with the lowest costs. ${ }^{64}$ Quite the opposite is true, as it creates an opportunity for incumbents to squeeze their more efficient competitors out of the market. ${ }^{65}$ This is an issue inseparable from that of slot trading, for if one assumes that an air carrier's willingness to pay for a given slot reflects the net increase in profit they are able to reap from that slot, efficiency would require that a slot goes to the operator who is prepared to offer the highest price for it. ${ }^{66}$ However, since monetary trading of slots is not officially endorsed (although the previous paragraph showed the existence of a 'grey market' for such activities), the system will not guarantee that slot holders are those carriers for which the slots have the most value. In other words, the system offers no incentives to transfer slots to more efficient competitors. ${ }^{67}$

\footnotetext{
59 Jörg Bauer, 'Do Airlines Use Slots Efficiently?' in Czerny, Forsyth, Gillen and Niemeier (n 36) 151.

${ }^{60}$ ibid. 154. One must note that this rule could be temporarily suspended due to external disturbance factors. It has been waived, once following the events of 11 September 2001, and again on the occasion of the Iraq war and the SARS epidemic in 2003.

61 This particularly includes routes subject to a Public Service Obligation (PSO). Carriers may be obliged by public authorities to operate on routes which are not commercially viable but which are necessary to operate for reasons of the general interest. Regulation 1008/2008 (Regulation (EC) 1008/2008 of the European Parliament and of the Council of 24 September 2008 on common rules for the operation of air services in the Community [2008] OJ L293/3) provides that to take into account the special characteristics and constraints of the outermost regions, in particular their remoteness, insularity and small size, and the need to properly link them with the central regions, Member States may impose a Public Service Obligation in respect of scheduled air services between an airport in the EU and an airport serving a peripheral or development region in its territory or on a thin route to any airport on its territory any such route being considered vital for the economic and social development of the region which the airport serves. Primarily the entrusted operator is required to offer a minimum daily service frequency and/or number of seats. There are often specific timetabling requirements with which the carrier must comply. On PSOs see further inter alia Ulla Neergaard, 'Services of General Economic Interest: The Nature of the Beast' in Markus Krajewski, Ulla Neergaard and Johan Van de Gronden (eds), The Changing Legal Framework for Services of General Economic Interest in Europe. Between Competition and Solidarity (DJØF 2009) 17; Elisenda Malaret Garcia, 'Public Service, Public Services, Public Functions and Guarantees of Rights of Citizens: Unchanging needs in a Changed Context' in Mark Freedland and Silvana Sciarra (eds), Public Services and Citizenship in European Law. Public and labour law Perspectives (OUP 1998) 57.

${ }^{62}$ Condorelli (n 1) 83.

63 ibid.

${ }^{64}$ ibid.

65 Valerie Corduant and Jean Louis van de Wouwer, One Sky for Europe? World-Wide Challenges (Bruylant 2001) 34.

66 ibid.

${ }^{67}$ The following deficient pattern of behaviour by carriers is the direct result of the current regulatory regime: First Airline and Second Airline hold heterogeneous valuations for three
} 
On the contrary, from the incumbent's perspective it constitutes a sound business decision to withhold a slot under their from entering the pool in order to thwart a competitor's (new entrant) expansion on a given market. ${ }^{68}$ One may suppose that maintaining loss-generating operations just to ensure a slot's utilization (which is a conditio sine qua non for retaining that slot) may be a better choice - from a business perspective - for an incumbent airline than to let a new entrant into a given airport. ${ }^{69}$ This is all the more so true considering that historical precedence usually covers peak-time slots, allowing for operations in convenient hours which, in turn, is reflected in profit earned. ${ }^{70}$ Thus airlines which would have to surrender slots would resort to 'hoarding' and rearrange their schedules in order to give up slots with the lowest commercial value. ${ }^{71}$

This is the main reason why the trade-off between the interests of incumbents and those of new entrants encapsulated in the 'use-it-or-lose-it' rule has failed to fulfil its mission, as it secures an insufficient number of slots for new entrants to begin truly competitive operations. ${ }^{72}$ This is particularly so when considering, as previously mentioned, that these 'forfeited' slots (returned to the pool) are usually off-peak - early in the morning or late at night - which makes connections less competitive. ${ }^{73}$ Therefore, despite the declared raison d'être of the current system, new entrants usually begin their operations from less favourably placed slots which, in turn, has a negative impact on the overall competitiveness of the market. ${ }^{74}$

slots $A, B$ and $C$ under the following values: First Airline; Slot $A-a$; Slot $B-b$; Slot $C-c$. Second Airline; Slot $A-a+d$; Slot $B-b+d$; Slot $C-c-d[a, b, c, d \geq 0 ; c>d]$. The value of the set of slots is the total of values attributed to each slot. When $d>0$ Second Airline values slots $A$ and $B$ more than First Airline does, while it values slot $C$ less. From an efficiency perspective slots $A$ and $B$ would be allotted to Second Airline and slot $C$ should go to First Airline realizing a total value of $v_{S}(A, B)+v_{F}(C)=a+b+c+2 d$. When $d=0$ every allocation is effective as the maximum value will be equal to $a+b+c$. Under the present system, when First Airline holds slots $A$ and $C$ and Second Airline holds slot $B$, efficient allocation could not be achieved as the former airline would not freely pass slot $A$ to the latter carrier. Assuming that trading (monetary exchanges) is allowed, First Airline could sell slot $A$ to Second Airline, and in turn the following efficient result would be achieved: $v_{F}(A)=a<P_{A}$ $<a+d=v_{S}(A)$.

${ }^{68}$ See research on the behaviour of dominant carriers in the USA by Severin Borenstein. Severin Borenstein, 'Hubs and High Fares: Dominance and Market Power in the U.S. Airline Industry' (1989) 20 RAND Journal of Economics 344.

${ }^{69}$ In the case of large network carriers, income from each particular route should never be assessed individually, in isolation from other connections in the carrier's entire network. The total network forms an interrelated cohesive structure and the overall profitability of this network should be the main concern, not its individual parts. This is especially the case if these secondary routes provide feeder service for the primary revenue-generating connections. See infra (n 81).

${ }^{70}$ John Balfour, 'Some Lessons from the European Experience', (1995) XX AASL 497.

${ }^{71}$ Stainland (n 2) 177.

72 ibid. For example, at London Heathrow airport at the time of introduction of the current slot distribution system (1993), out of a total 7558 slots of weekly capacity 94.7 per cent were covered by the grandfather rule. After one year only 35 slots ( 7 per cent) were returned to the pool under the 'use-it-or-lose-it' rule.

${ }^{73}$ Balfour (n 69) 497-508.

$74 \mathrm{ibid}$. The lack of slots is not a real entry barrier but their virtually non-existent commercial value is. So-called 'moonlight slots' are slots that are commercially useless because they 


\section{THE OUTLOOK FOR REFORM - ALTERNATIVE APPROACHES}

The aforementioned system has been criticized for such deficiencies as leading to sub-optimal slot allocation. Taking into account experiences with the current system, on the eve of its reform it is worth exploring some alternative regulatory approaches to the issue under examination.

\section{a) Auctioning}

Possible solutions to the slot trading problem constitute the point of departure for this analysis. The first of the discussed options will be the mechanism of slot auctioning. Under this system, airlines would be able to purchase slots on the basis of the best price offer. ${ }^{75}$ Essentially this means that a slot would go to the carrier willing to offer the highest price. Of course this approach would (at least in principle) presume that slots are indeed property rights and that selling them would imply full transfer of their ownership to airlines. ${ }^{76}$ Furthermore, an auctioning system raises serious concerns on both practical and political grounds. ${ }^{77}$ One may argue that such a system creates the risk that new entrants would be outbid by incumbent operators as the difference in bidding power between major flag carriers and de novo entrants would allow for such practices. ${ }^{78}$ At the same time, these risks could be mitigated by phasing in the auction process, with only a certain percentage of slots being auctioned each year (each reference period). ${ }^{79}$

While the general logic behind the auction mechanism is simple, the choice of particular method is not. The prime objective of slot auctioning is allocative efficiency, but one must also take into account the specifics of airline operations in respect of schedule planning. The chief issue that emerges here is the so-called 'aggregation problem' ${ }^{80}$ In a nutshell, from the airlines' perspective certain combinations of slots have a higher value than sum of the individual values of each of these slots. ${ }^{81}$ This is especially important for carriers operating under the hub-and-spoke system in which securing specific slots is vital for creating the synergy effect necessary in the

grant a right to take-off or land at times where there is no demand for the air services in question, i.e. during off-peak periods late at night (at 'moonlight') or at weekends. An airline therefore can always apply for a moonlight slot with the intention to merely use it as 'bait' for a slot trade with another airline. Kilian (n 45) $25 € 7$.

${ }^{75} \mathrm{In}$ economics, an auction is a process of buying and/or selling goods or services by offering them up for a bid and may refer to any specified mechanism (Vijay Krishna, Auction Theory, ( $2^{\text {nd }}$ edn, Elsevier 2010)). In this paper the term 'auction' will be used in this broad sense unless explicitly linked to a specific mechanism under discussion.

${ }^{76}$ While the basic economic logic of an auction implies the existence of a property right on a given asset, it is also entirely possible to regard slots as a temporary utilization licence (of a runway). See discussion in Boyfield (n 36) 21.

77 Stainland (n 2) 180 - 181; Rigas Doganis, Flying off course. The Economics of International Airlines. ( $3^{\text {rd }}$ edn, Routledge 2002) 106 - 108.

${ }^{78}$ ibid.

79 This solution is a response to concerns voiced by the airlines (Morris n 66). Additionally, routes with Public Service Obligations would be excluded from auctioning. See supra (n 60).

${ }^{80}$ Franklin M. Fisher, 'Aggregation Problem' in Steven N. Durlauf and Lawrence E. Blume (eds), The New Palgrave Dictionary of Economics (Palgrave-MacMillan 1987) 53.

${ }^{81}$ Condorelli (n 1) 88 - 89. 
integration of the arrival and departures network (and sustaining hub-andspoke operations). ${ }^{82}$ In the case of the simplest method of auctioning, which could be described as 'one slot-one auction', achieving this synergy would be next to impossible and would result in the system effectively dismantling all hub-and-spoke operations, while depriving the market of the predictability and continuity of the current grandfathering system. ${ }^{83}$ For these reasons, a simple system of separate auctions for individual slots would fail to ensure allocative efficiency. ${ }^{84}$ In a dynamically interdependent environment (air transport has a tendency to foster oligopoly) one may also argue that the demise of cohesive networks would be detrimental to consumers/passengers.

One of the possible solutions to address these concerns and, to a certain extent, alleviate the aggregation problem is the Vickrey auction (otherwise known as the Vickrey-Clarke-Groves system). ${ }^{85}$ This system is designed to ensure equilibrium between efficient allocations of certain goods (slots) regardless of the information held by each bidder about competitors particularly about their bidding power. In practice this mechanism works as follows: each bidder submits a complete list of valuations, one for each possible bundle of items. In the next step, the auctioneer determines the most efficient allocation on the basis of the submitted values. ${ }^{86}$ Then, the bidders are requested to pay the opportunity cost for their participation, which effectively means they are to pay the difference between the value of the efficient allocation that would have been selected if the submitted value had equalled zero for all bundles and the value that the other bidders obtain under the efficient allocation selected by the auctioneer upon considering all

\footnotetext{
82 The hub-and-spoke system (distribution paradigm) in air transport is based on a system of large airports, hubs. Put simply, a passenger wishing to journey from point A to point B uses a regional airline (feeder) to reach the nearest hub, from which travel then continues to the hub closest to the destination. The passenger then uses a regional airline to reach that destination. Compared to a point-to-point network of $\mathrm{n}$ nodes, in a hub-and-spoke system only $n-1$ routes are required to reach the same number of destinations. This is because the upper bound is $x-1$, and the complexity is $0(x)$, which compares favourably to the $\frac{x(x-1)}{2}$ routes on $0\left(n^{2}\right)$ required to connect every point in the network (in the case of 10 points the hub-and-spoke model would require 9 routes, while the alternative point-to-point approach 45). Most major carriers operate according to this model, although the majority of the heavily hub-oriented carriers in fact apply a hybrid model which includes a limited number of point-to-point services not connected with a hub. Of course one must also take into account a multitude of other demand-related, technical, etc. considerations in setting up a route network, so the final shape of a network goes beyond factors related merely to the number of flights necessary to connect all airports in a given system. For details see inter alia Peter Belobaba, 'The Airline Planning Process' in Belobaba, Odoni and Barnhart (n 3) 153, especially 163; Gillaume Burghouwt, Airline Network Development in Europe and its Implications for Airport Planning (Ashgate Publishing 2007) Annex I: Definition of the Huband-Spoke Network 257.

${ }^{83}$ Gruyer and Lenoir (n 47) 10.

84 ibid.

85 The theorem owes its name to and has been generalized by William Vickrey, Edward $\mathrm{H}$ Clarke and Theodore Groves. See William Vickrey, 'Counterspeculation, Auctions, and Competitive Sealed Tenders' (1961) 16 Journal of Finance 8; Edward H Clarke, 'Multipart Pricing of Public Goods' (1971) 11 Public Choice 17 and Theodore Groves, 'Incentives in Team' (1973) 41 Econometrica 617.

${ }^{86}$ Condorelli (n 1) 93; Krishna (n 74) 229.
} 
reports. ${ }^{87}$ In other words, the buying party pays what it costs the others by taking part in the auction. ${ }^{88}$

From the regulator's perspective, this system offers a serious advantage as one of its main features is the possibility to impose distribution constraints which may be indispensable in achieving policy-defined goals. ${ }^{89}$ Assuming certain restrictions (for example, that specific slots should be allotted to certain categories of carriers) are in place, operators will still be well-advised to submit bids that are equal to their true values, and the payment will be calculated as the optimum value under that constraint. ${ }^{90}$

Another possible mechanism for slot auctioning is the so-called clockproxy auction (Cryptographic Combinatorial Clock-Proxy). ${ }^{91}$ This mechanism consists of two phases: a clock auction and a proxy auction. It combines the simple and transparent price discovery of the former with the efficiency of the latter. ${ }^{92}$ Linear pricing is maintained as long as possible, but then is abandoned in the proxy phase to improve efficiency and enhance seller revenues. ${ }^{93}$ This procedure is constructed as follows: in the first step - the clock phase - the auctioneer announces prices for slots, and the bidders (airlines) respond with the number of slots they want in each time window (day, week etc.). ${ }^{94}$ The prices of licenses for time windows where demand for licenses exceeds supply are then increased (up to the total supply level), and a new round begins. ${ }^{95}$ This phase ends when no excess demand remains for

87 ibid.

${ }^{88} \mathrm{ibid}$. This sealed-bid auction is based on the following principles: a set of auctioned slots $M=\left\{t_{1}, \ldots, t_{m}\right\}$ and a set of bidders (airlines) $N=\left\{b_{1}, \ldots, b_{m}\right\}$. Now assuming $V_{N}^{M}$ is the social value of the discussed auction (for a certain combination). An airline $b_{1}$ which wins the slot $t_{j}$ will pay $V_{N \backslash\left\{b_{i}\right\}}^{M}-V_{N \backslash\left\{b_{i}\right\}}^{M}$ (social cost of the winning party is thus incurred by the other bidders). Any set of bidders other than $b_{i}$ is $N \backslash\left\{b_{i}\right\}$. In every situation when a given $\operatorname{slot}\left(t_{j}\right)$ becomes available, these carriers would attain welfare $V_{N \backslash\left\{b_{i}\right\}}^{M}$. Every auction resulting in sale of a slot to a certain bidder $b_{i}$ would reduce the total number of available assets to $M$ $\left\{t_{j}\right\}$ and change the attainable welfare to $V_{N \backslash\left\{b_{i}\right\}}^{M \backslash\left\{t_{j}\right\}}$. The winner will pay the difference between these two welfare values. This winner (who has value $A$ ) could thus derive the following utility (for slot $\left.t_{j}\right) \mathrm{A}-\left(V_{N \backslash\left\{b_{i}\right\}}^{M}-V_{N \backslash\left\{b_{i}\right\}}^{M \backslash}\right)$.

${ }^{89}$ Gruyer and Lenoir (n 47).

${ }^{90}$ One must also take into account the following factor: in order to calculate payment it is necessary to determine for each buyer acquiring a slot what the optimum allocation (under given constraints) would be if that buyer had not taken part in the auction, which in a realworld situation could be problematic.

${ }^{91}$ Lawrence M Ausubel and Paul Milgrom, ‘Ascending auction with package bidding' (2001) 1 Frontiers of Theoretical Economics 1; C Parkes, Michael O Rabin and Christopher A Thorpe, 'Cryptographic Combinatorial Clock-Proxy Auction' in Roger Dingledine and Philippe Golle (eds) Financial Cryptography and Data Security (Springer 2009) 305;

92 ibid.

93 ibid. Lawrence M.Ausubel and Peter Cramton, ‘Auctioning Many Divisible Goods' (2004)

2 Journal of the European Economic Association 480.

${ }^{2}$ ibid.

${ }^{95}$ Lawrence M. Ausubel, Paul Milgrom and Peter Crompton, 'The Clock-Proxy Auction: A Practical Combinatorial Auction Design' in Peter Cramton, Yoav Shoham, and Richard Steinberg (eds) Combinatorial Auctions (MIT Press 2006) 16-17. 
any time window. ${ }^{96}$ The raison d'étre of this step is to facilitate price discovery, as well as to remove the exposure problem, that is the risk of bidders paying an excessive price for a slot that is of no use without its complement slot (typical in the case of hub-and-spoke operations) ${ }^{97}$ By the end of the clock phase, airlines would be able to estimate the commercial value of each particular slot. ${ }^{98}$

The clock phase is followed by a proxy phase. ${ }^{99}$ Each carrier determines the value of slots it are interested in and then reports these values to a proxy agent. ${ }^{100}$ The proxy bids for the airline in an ascending package auction as follows: the proxy determines in round $X$ the potential profit for every possible bid using the reported values. ${ }^{101}$ The proxy then submits a bid corresponding to the maximum potential profit. ${ }^{102}$ The proxy round ends when no new bids are submitted. ${ }^{103}$ This phase is designed to counter the possibility of demand reduction or collusion as a result of the clock phase and

${ }^{96}$ In each round $t$, the price vector $p^{t}=\left\{p_{1}^{t}, \ldots, p_{m}^{t}\right\}$ associated price with each asset $p_{j}^{t}$ is the price for slot $S_{j}$ in round $t$. Bidders submit bids $s_{i}^{t} \in \mathbb{Z}_{\geq 0}^{m}$ in each round. The clock round ends when demand is smaller than supply.

${ }^{97}$ Ausubel, Milgrom and Crompton (n 94) 17. The exposure problem typically appears when a buyer with complementary valuations bids to acquire a set (bundle) of assets (slots) sold in sequence during independent auctions. In typical sector-related situations, when a hub-andspoke carrier (supra n 81) seeks to obtain a certain combination of slots (which are sold separately) it faces the exposure problem as it requires this particular combination of slots to achieve the synergy effect indispensable for network cohesion. For a detailed analysis of this problem see inter alia Craig Boutilier, Moises Goldszmit and Bikash Sabata, 'Sequential Auctions for the Allocation of Resources and Complementarities', [1999] Proceedings of the 16th international joint conference on Artifical intelligence - Volume 1 527;

${ }^{98}$ See impact assessment regarding the introduction of proposed clock-proxy auctioning at high-density New York LaGuardia airport (due to its proximity to the centre of the New York Metropolitan Area this airport is the busiest in the United States in terms of flight operations and thus is particularly prone to congestion). Aidan D Smith, 'LaGuardia Slot Allocation: A Clock-Proxy Auction Approach', [2004] Econ 41515.

${ }^{99}$ Condorelli (n 1) 94. In the transition to the proxy phase, if $T$ means the total number of rounds in the proxy phase, each of the airlines submitted bid $\left\{s_{i}^{1}, \ldots, s_{i}^{T}\right\}$ bundles at public prices $\left\{p^{l}, \ldots, p^{T}\right\}$. The airline (bidder) can now do one of the following: in the first scenario, the airline could improve the bids submitted during clock phase (the bid price must satisfy $\left.b_{1}\left(s_{i}^{t}\right) \geq p^{t} \cdot s_{i}^{t}\right)$. In the second case, the airline could submit additional bid(s) (considering a bundle of assets $s_{i}^{k}$ and either a new bundle or those remaining from the clock phase and its associated bid price $b_{i}\left(s_{i}^{t}\right)$ with every bid. This bid must thus satisfy $b_{i}\left(s_{i}^{k}\right)-p^{t} \cdot s_{i}^{k} \leq$ $\left.\alpha\left(b_{i}\left(s_{i}^{t}\right)-p^{t} \cdot s_{i}^{t}\right), \forall t \in\{1, \ldots, T\}\right)$.

100 ibid.

${ }^{101}$ Parkes, Rabin and Thorpe (n 90) 315.

102 ibid.

103 The primary merit of this mechanism (phase) lies in the fact that it ends with a core allocation for the reported preferences. If coalition forms a pair $(L, w)$ where $L$ denoted the number of airlines (bidders, where $l=0$ for the seller), then if $\mathrm{W}(\mathrm{s})$ is the value of coalition $\mathrm{S}$ and where $X$ denotes the set of feasible allocations $\left(x_{l}\right)_{l \in L}$. Now, if S excludes the seller, then $w(S)=0$. On the other hand, where $\mathrm{S}$ includes the seller then $\mathrm{w}(\mathrm{S})=\max _{x \in X} \sum_{l \in S} v_{l}\left(x_{l}\right)$. The core $(L, w)$ is the set of all imputations of $\pi$ which are payoffs imputed to the bidders based on allocations that are feasible for the coalition as a whole. This could not be blocked by any coalition $S$. That is for any coalition $\sum_{l \in S} \pi_{l}\left(x_{l}\right) \geq w(S)$. Therefore the proxy phase offers two main advantages: efficiency and competitive revenues for the seller. Ausubel, Milgrom and Crompton (n 94) 9. 
to promote efficiency. ${ }^{104}$ In other words, the proxy phase allows for safe bidding for synergies which are indispensable to hub-and-spoke operations. $^{105}$

The third option of relevance here is a first-price package auction (combinatorial auction). ${ }^{106}$ The underlying principle of this system is that an airline submits bids for a certain number of slots (a package) but it only pays when it gets them all. ${ }^{107}$ This is the simplest auction mechanism, which essentially operates on an "all or nothing" basis. ${ }^{108}$ As mentioned before, the value of a certain combination of slots to network carriers is much higher than the combined value of an equal number of individual slots. ${ }^{109}$ For these operators the "all or nothing" principle in the slot acquisition process serves as a tool for maintaining network cohesion and integrity. ${ }^{110}$ In this system, determining the winning bidder can be a complex process under which the party with the highest individual bid is not necessarily guaranteed to win. ${ }^{111}$

\section{b) Secondary Trading}

Under the current legal regime, while slot trading is not officially endorsed, it does occur. ${ }^{112}$ From a theoretical perspective this approach enables parties to acquire only the slots of greatest value to them, and the

\footnotetext{
${ }^{104}$ With complete information this phase reaches an efficient Nash equilibrium. For details see Douglas B Bernheim and Michael B Whinston, 'Menu Auctions, Resource Allocation and Economic Influence' (1986) 101 Quarterly Journal of Economics 1.

${ }^{105}$ See supra (n 81) and (n 96).

106 See Paul Milgrom and Robert J Weber, 'A theory of auctions and competitive bidding' (1982) 50 Econometrica 1089.

${ }^{107}$ The mechanism operates as follows: each bidder $b$ makes a set of non-negative sealed bids $\left\{\beta^{b}\left(x^{b}\right)\right\}_{x^{b} \in X^{b}}$. The auctioneer (e.g. airport authority, regulator) maximizes the objective $\sum_{b=l}^{N} \beta^{b}\left(x^{b}\right)+v^{0}(x)$ which is the sum of the bids plus the seller's value for the allocation. Now, the bidder pays the amount of its winning bids, so if the seller chooses $x$, the airline $b$ 's (original bidder's) payoff is $v^{b}\left(x^{b}\right)-\beta^{b}\left(x^{b}\right)$. See Paul Milgrom, Putting Auction Theory to Work (CUP 2004) 317.

${ }^{108}$ Milgrom and Weber (n 105) 1090.

${ }^{109}$ Condorelli (n 1) 88 - 89; Belobaba (n 81) 153 and Burghouwt (n 81) 257.

110 ibid. See also supra (n 81) and (n 96).

${ }^{111}$ Milgrom and Weber (n 105) 1089 - 1122. Of course, these auction mechanisms are not mutually exclusive as, for example, the Federal Aviation Administration (FAA) and Department of Transportation (DoT) proposed a system for LaGuardia Airport where each year a limited number of slots are intended to be auctioned off by a package clock-proxy action while the rest are done so through a sealed-bid package auction. Smith (n 97); Bernardino, 'Market Pricing of Airport Access and the EU-US Liberalization', Presentation at the AirNeth Conference 14 April 2008. Available: http://www.airneth.com/index2.php?option $=$ com_docman\&task $=$ doc view\&gid=608\&Item $\underline{\mathrm{id}=15}$ (accessed 20 December 2012).

112 Allan, Furse and Sufrin (n 42) IX-305; Stainland (n 2) 176; The challenges of clarifying 'ownership' (assuming that slots indeed amount to a property right) for the purposes of the primary allocation of slots need not prevent the definition of tradable rights in slots and legitimising a secondary market. Tradable rights short of "freehold" rights could be defined and efficiency gains realised through secondary trading. In a competitive market slots ought to move to those who value them the most irrespective of their initial allocation. The issue of "ownership" and any distribution of the rent lying behind slot rights should thus be considered as a separate policy decision. [Civil Aviation Authority (CAA), The Implementation of Secondary Slot Trading (CAA 2001) 2].
} 
ultimate result will be efficient regardless of the initial allocation. ${ }^{113}$ Under the current system, in which assets (slots) are given away for free, no financial impact assessment prior to slot acquisition is required on the side of airlines. To put it bluntly, since carriers are not paying they have no interest in obtaining only those slots which they would use effectively. Unused slots return to the pool at the end of a given reference period without any financial downside for their previous holders. This inefficient allocation is harmful to the overall competitiveness of the market as unused slots could be put (at least potentially) into better use by competitors and/or new entrants. ${ }^{114}$ Commercialization of slot trading means the purchasing party will be required to give information about their own valuations through pricing, which in turn would establish a properly-constituted market, especially when all transactions are publicly registered. ${ }^{115}$ The argument goes that regardless of how slots are initially allotted (for example, by a coordinator), in the case of secondary trading efficiency will be attained in any case. ${ }^{116}$ Airlines will sell slots that are unused or that generate insufficient revenue. ${ }^{117}$

While the underlying economic rationale behind the secondary trading system is valid, certain sector-specific factors reduce the practical feasibility of this system. Exchanges with optimal efficiency do not occur in situations of asymmetric information which are unavoidable in real-world scenarios. ${ }^{118}$ Furthermore, since the data leading airlines to acquire a slot is generally regarded as trade sensitive and thus are kept secret, there is no bargaining mechanism (protocol) ensuring that transactions will be conducted with peak efficiency. ${ }^{119}$

Furthermore, secondary trading raises concentration concerns on downstream markets. This applies chiefly to airports with a dominant carrier

\footnotetext{
113 Mott MacDonald, Study on the impact of the introduction of secondary trading at Community airports. Volume 1 (European Commission 2007). Also, from the efficiency standpoint the difference between primary and secondary trading is minor as the mechanism of initial allocation is largely irrelevant. This is because regardless of whether the primary allocation is through trading or administrative mechanisms, it would still require a follow-up distribution mechanism for returned slots, which in the case discussed is the secondary trading.

${ }^{114}$ Condorelli (n 1) 83; Corduant and van de Wouwer (n 64) 34; Stainland (n 2) 175.

115 Based on the experience of slot allocation in British airports (particularly in the London system), the CAA is supporting secondary trading on these grounds. CAA (n 112).

${ }^{116}$ Stainland (n 2) 179-180.

${ }^{117}$ Condorelli (n 1) 95.

118 Information asymmetry relates to a situation where in a transaction-related decision process one party has better information than another, which creates imbalance. Without going into details which are beyond the scope of this paper, the assumption of the existence asymmetric information is more than obvious.

${ }^{119}$ Assuming First Airline (F) holds slot A and that $v_{\mathrm{F}}(\mathrm{A})=x \leq 1$, while $v_{\mathrm{S}}(\mathrm{A})=y \leq 1$. Now, assuming that both airlines (First and Second $[\mathrm{S}]$ ) are not aware of each other's value for a given slot (A) but both of them are making an assessment of it, which is a random variable. According to the theorem under discussion, no bargaining protocol could ensure optimal efficiency for every $x$ and $y$. At the same time the outcome will not be acceptable to both of the airlines concerned. Under this mechanism, a given slot will be assigned to Second Airline if $y>x$ and to First Airline otherwise. For details on bargaining protocol see Roger B. Myerson and Mark A. Sattherwaite, 'Efficient Mechanism for Bilateral Trade' (1983) 29 Journal of Economic Theory 265.
} 
which usually owes its position to the pre-liberalization conditions. ${ }^{120}$ The risk is that airline may use its superior financial power (compared to that of other operators) to engage in predatory behavior by pre-empting the entry of slots into the market. ${ }^{121}$ In other words, the system allows for a greater scope of anti-competitive behavior on the part incumbent operators. ${ }^{122}$ However, data regarding slot usage at the most heavily congested airport in the US shows that the pattern of behavior displayed by dominant airlines usually reflects the pursuit of effectiveness in slot usage rather than anti-competitive practices. ${ }^{123}$ One must also take into account that higher fares of dominant airlines may not necessarily be a result of infringement of competition rules, but may be the net result of diseconomies of scale in other network operating costs associated with the operations of a given airline. ${ }^{124}$ In other words, the overall pattern of behavior of a dominant carrier depends on a multitude of factors (e.g. inter-airport competition, route dominances), so it seems farfetched to conclude that the secondary trading system generates anticompetitive behavior. ${ }^{125}$ Therefore, notwithstanding the aforementioned shortcomings, experiences with secondary markets (from the USA and UK) indicate that they indeed yield rather positive results. ${ }^{126}$ The data shows that this system is, to a certain extent, able to foster competition and facilitate new entries. $^{127}$

\section{c) Administrative Regulation}

Administrative regulation could be perceived as the total opposite of the auction and trading systems. It is based on the assumption that slots are public property and public authorities should thus be responsible for their allotment. ${ }^{128}$ This line of reasoning takes its point of departure from the

\footnotetext{
${ }^{120}$ Supra (n 55). On the market situation prior to liberalization see inter alia Kenneth $\mathrm{J}$ Button, 'Aviation Deregulation in the European Union: Do Actors Learn in the Regulation Game?', (1996) 14 Contemporary Economic Policy 70; Francis McGowan, Paul Seabright, 'Deregulating European Airlines', [1989] Economic Policy 283; Richard W. S. Pryke, 'American Deregulation and European Liberalisation Transport in a Free Market', in Kenneth J Button, David Banister (eds), Transport in a Free Market Economy (MacMillan 1991) 220.

121 Jaap de Wit and Guillaume Burghouwt, 'Slot Allocation and Use at Hub Airports, Perspectives for Secondary Trading', (2008) 8 EJTIR 147.

122 ibid.

${ }^{123}$ Andrew N Kleit and Bruce H Kobayashi, 'Market Failure, or Market Efficiency? Evidence on Airport Slot Usage', (1996) 4 Research in Transportation Economics 1; David Starkie, 'Allocating Airport Slots. Role for the Market?' (1998) 4 Journal of Air Transport Management 111. However, research by Severin Borenstein and the U.S. Government Accountability Office (GAO) produced contradictory results: Borenstein (n 67); GAO, Airline Deregulation: Changes in Airfares, Service Quality, and Barriers to Entry (GAO/RCED-99-92 1999).

124 These may include network-related factors as: economics of scale, network scope and density as well as costs associated with operating from a particular hub (airport) as baggage handling, turn-around times of operation, ground staff etc.

125 de Wit and Burghouwt (n 120) 147; Jaap de Wit and Guillaume Burghouwt, The Impact of Secondary Slot Trading at Amsterdam Airport Schipol, SEO Economic Research Report/SEO economisch oonderzoek(Ministerie van Verkeer en Waterstaat; V\&W 2007).

126 ibid; CAA (n 112).

127 ibid.

${ }^{128}$ Stainland (n 2) 179.
} 
assumption that commercialization of slots would result in the incumbent flag carriers achieving dominance. ${ }^{129}$ The argument runs that the greater resources available to these carriers allows them to buy up most of the valuable slots and thus effectively thwart the competition. ${ }^{130}$

In spite of these concerns, the merit of administrative regulation lies in the possibility to protect routes regarded as economically and politically important. ${ }^{131}$ The real impact of this method can only be assessed by analysing specific regulatory approaches. ${ }^{132}$ In other words, everything depends on how 'interventionist' the policy pursued by a given regulatory body is. ${ }^{133}$

\section{d) Congestion Pricing}

Congestion pricing is a system for charging users of goods that are subject to congestion though excess demand, of which airport runways are a textbook example. The idea behind congestion pricing comes from the standard economic theory of efficiency and externalities. ${ }^{134}$ In the situation discussed here, this system means increasing airport charges at peak times while reducing them in periods of low demand. ${ }^{135}$ Charges aimed at flattening demand during the busiest hours and increasing it during less popular hours will allow for better control of the traffic flow within an airport system. ${ }^{136}$

It is suggested that consumers (passengers) will eventually respond to higher peak pricing. ${ }^{137}$ In general, passengers consider peak-hour flights as

\footnotetext{
129 Supra (n 39).

${ }^{130}$ Impact analysis of usage of airlines' resources on the overall competitiveness of the market has not produced results sufficient to reach the conclusion that these concerns are fully justified. Anti-competitive concerns are supported by research by Kleit and Kobayashi (n 123) and Starkie (n 123). Contrary evidence is found in the research of Borenstein (n 123) and GAO (n 123).

131 Stainland (n 2) 179.

${ }^{132}$ In fact, it is not necessarily to adopt a 'pure' administrative regulatory model (all slots are allotted through this method). It is much more realistic to apply the so-called 'mixed regulatory approach' in which the regulator establishes general procedures and criteria but their interpretation is left a certain discretion. Doganis (n 77).

133 ibid.

134 Over the years there has been considerable acquis of doctrine regarding economic perspectives of airport congestion pricing in respect to slot allocation. See inter alia Cristina Barbot, 'Airport Pricing Systems and Airport Deregulation Effects on Welfare' (2005) 10 Journal of Air Transportation 109; Leonardo J Basso and Ammin Zhang, 'Pricing vs. slot policies when airport profits matter' (2010) 44 Transportation Research Part B 381; Jan K Brueckner, 'Airport Congestion When Carriers Have Market Power' (2002) 92 The American Economic Review 1357; Alan Carlin, and Rolla E Park, 'Marginal cost pricing of airport runway capacity’, (1970) 60 American Economic Review 310; Eric Pels and Erik T Verhoef, 'The Economics of Airport Congestion Pricing' (2004) 55 Journal of Urban Economics 257.

135 ibid.

${ }^{136}$ Regulators could vary charges not only between peak and off-peak operations but also depending on the weight of the aircraft. These differences may aim at discouraging general aviation, which has no effect of relieving congestion while having analogous capacity requirements to those of commercial operations.

137 Paul Nibbering, 'Managing Airport Congestion - the Effects of Runway Peak Pricing' (2009) 41 Aerlines 1.
} 
high-quality products and off-peak flights as low-quality products. ${ }^{138}$ According to this line of reasoning, such a system will ensure that the prices of air services will reflect the commercial value of the slots they are associated with, in turn guaranteeing efficient usage of slots. ${ }^{139}$

The main shortcoming of this system lies in the fact that competitive equilibrium of prices only exists when slots are substitutes for all airlines. ${ }^{140}$ In real-world conditions, certain combination of slots are complementary for some airlines (especially hub-and-spoke operators) but substitutes for others. ${ }^{141}$ It also seems unrealistic that airport management or regulators will have adequate information in each reference period to compute market clearing prices. ${ }^{142}$ The pricing scheme will perform its task only when values are known in advance while the quantity available is unknown, as market mechanisms will determine the latter. ${ }^{143}$ In the case discussed here, the total number of available slots is fully known in advance while their values for the airlines (the maximum price carriers will be willing to pay) are not. ${ }^{144}$ In other words, the system is prone to the occurrence of two possible scenarios, both of which would generate suboptimal results (deficiencies). ${ }^{145}$ In the former, if the price threshold is set at an inadequate level (too low), it will fail to deliver the expected result of leveling demand between peak and off-peak. The additional costs associated with operations during the tolled period in this case would simply be insufficiently high for carriers to rearrange their schedules, ${ }^{146}$ while in the latter case, if congestion charges are set at excessive levels, in extreme cases carriers may even withdraw from a given airport. ${ }^{147}$

\footnotetext{
138 ibid.

${ }^{139}$ Brueckner (n 134); Czerny, Forsyth, Gillen and Niemeier (n 36) 3; Pels and Verhoef (n 134).

${ }^{140}$ For the purpose of this analysis, slots are regarded as substitutes if increasing the price for one slot does not decrease demand for another slots whose prices remain unchanged.

${ }^{141}$ This issue could be illustrated by the following example. Two slots (A and B) are available at a given airport. Two Airlines First $(F)$ and Second $(S)$ are considering their acquisition according to the following values: First Airline: Slot A $-c$; Slot B $-c$; Slots A and B $-2 c+d$. Second Airline: Slot A $-c+0.6 d$; Slot B $-c+0.6 d$; Slots A and B $-c+0.6 d[c, d>0]$. Slots are complements for First Airline (e. g. due to hub-and-spoke network requirements) and substitutes for Second Airline. From the efficiency standpoint slots should be allotted to the First Airline, but there is no set of prices $\left\{P_{A}, P_{B}\right\}$ that can ensure that. It follows that First Airline should buy slots (which is the efficient solution): $P_{A}+P_{B} \leq 2 c+d=v_{F}(A, B)$. This may mean one of the following. First; $P_{A}<c+0.6 d=v_{S}(A)$ or second $P_{B} \leq c+0.6 d=v_{S}(B)$. In any case, Second Airline will still demand one of the given slots [Source: Condorelli (n 1)].

${ }^{142}$ de Wit and Burghouwt (n 125).

143 Condorelli (n 1) 89.

144 ibid 90.

145 Despite these efficiency-based concerns one must also take into account distributionrelated aspects of the scarcity of runway slots. There are small but notable differences between the net welfare gains between atomistic and optimistic congestion pricing policies. Considering both efficiency-related and equity-related factors of the pricing mechanism, the introduction of atomistic tolls seems to render a more feasible solution without substantial loss of efficiency. See Steven A Morrison and Clifford M Winston, 'Another Look at Airport Congestion Pricing' (2007) 97 American Economic Review 1970.

146 Basso and Zhang (n 134); Brueckner (n 134); Pels and Verhoef (n 134) 275.

147 This scenario would chiefly depend on how many other airports are within so-called 'catchment area'. Whether an adjacent airport would provide a suitable alternative depends on a number of factors such as convenience of access. In other words, the key question is the
} 


\section{CONCLUSION}

Analysis of the manner in which the EU's present slot allocation system functions clearly shows that it has failed to sufficiently address the associated problems. This is chiefly due to insufficient numbers of slots being returned to the pool for distribution to new entrants. Also, one may criticize lex lacunae in the field of secondary trading, as airport congestion and the associated service disruptions continue to grow, causing constantly increasing losses to airlines and the whole European economy. Yet despite widespread recognition of the shortcomings of the current slot allocation system, the parties involved have failed to reach a consensus on how to reform it. This lack of agreement regarding measures that should be adopted to ameliorate the slot allocation problem is the result of a multitude of essentially political factors. Each of the discussed proposals has its advantages and drawbacks for various interest groups involved in the decision-making process: airlines, local residents, airport management, etc. Therefore, gaining political support for a given solution would require striking a fine balance between the interests of these diverse parties. This practical consideration means that the final revised slot regulation will have to go beyond purely economic considerations of efficiency. In other words, a certain trade-off between conflicting policy goals is inevitable. Thus the focus should not be put on finding an optimal solution, but rather the workable 'second-best' - one that would receive the necessary political backing.

Apart from all these factors, another layer which adds to the complexity of the problem is the competition policy issue. Without going into an in-depth analysis which is beyond the scope of this paper, responsible lawmaking has to take into account several key considerations. First and foremost among them is safeguarding against exploitation of market power by incumbent carriers, both during auctions and secondary trading. This scrutiny must encompass both anti-competitive behavior (e.g. abuse of dominant position, concerted practices) as well as mergers and acquisitions (those involving redistribution of slots). Since slot allocation has a monetary element, the question of compatibility with state aid rules emerges, both for the funding of regular slot purchases and those with Public Service Obligations (PSO) imposed. However, even if one could brush these considerations aside and ignore policy-defined constraints, there would still be no clear-cut answer as to which of the discussed alternative approaches would best resolve the slot conundrum. Since a significant increase in airport capacity is not a viable option for many reasons that were outlined at the beginning of this paper (while it would be the single best solution), after giving the matter due consideration a system mixing secondary trading with

level of competition between airports. Therefore, for apparent reasons, for most of the fullservice carriers there are no viable alternatives to major hub airports. But the level of airport charges at these airports is the primary reason why low cost airlines operate form airports of secondary importance which naturally offer lower fees. See also: Sean D Barret, Deregulation and the Airline Business in Europe: Selected Readings (Routledge 2009) 120; G Germà Bel, Xavier Fageda, 'Privatisation, regulation and airport pricing: an empirical analysis for Europe' (2010) 37 Journal of Regulatory Economics 142. 
auctions (preferably clock-proxy) seems to be the most desirable. The analysis provided above demonstrates the plethora of concerns regarding these mechanisms, but nevertheless, in the author's opinion the pros outweigh the cons for the following reasons:

It seems that commercialization of the slot exchange process either through auctions or secondary trading would force carriers to rationalize their network structure by selling those slots that could not be put into effective, revenue-generating use. To achieve this efficiency objective the system should be designed on the basis of two stages of allocation in the following sequence: tier-one allocation of slots should be performed through auctions, and after initial distribution, during the tier-two phase the airlines should be authorized to sell slots. This is only a basic outline of the system as there are several crucial issues that must be addressed in the system design phase.

The first of these issues is the exact number of years that should elapse between auctions, which should be determined through further research. Excessive frequency in auctions will add to the volatility of airlines' costs, which in turn would increase capital costs. On the other hand, if most of the allocation were left to the secondary market, the market prices of slots would rise to a very high level, meaning that the amount of financial resources required to obtain slots will force smaller operators in particular to fall short of budget or risk insolvency. Therefore, secondary trading alone will not ensure efficient allocation. Another issue centers around the choice of auction mechanism. The final issue, although closely related to the previous ones, relates to cash flow within the system. In other words, how should resources collected from auctions be used by the State? This decision will essentially be a political one. At the same time, secondary trading may require additional capital acquisition from the airlines, either through credits or subsidies, the latter of which is also clearly a policy issue. A comprehensive regulatory regime must address these issues, with particular emphasis on oversight. 